\title{
KAJIAN POTENSI INTERAKSI OBAT PADA PASIEN GLAUKOMA DI SALAH SATU RUMAH SAKIT DI BANDUNG
}

\author{
Ani Anggriani ${ }^{1, *}$, Pujani Utami ${ }^{1}$, Ida Lisni $^{2}$ \\ ${ }^{1}$ Sekolah Tinggi Farmasi Bandung (STFB) \\ ${ }^{2}$ Rumah Sakit di Bandung \\ *Email :anianggriani01@gmail.com
}

\begin{abstract}
ABSTRAK
Latar belakang: Glaucoma menempati urutan kedua (12,3\%)setelah katarak $(47,8 \%)$ sebagai penyebab kebutaan kedua diseluruh dunia.Interaksi Obat merupakan salah satu Drug Related Problems(DRPs) yang dapat mempengaruhi terapi pasien.Tujuan Penelitian adalah mengkaji potensi interaksi obat glaukoma pada pasien rawat jalan di salah satu rumah sakit di Bandung. Metode Penelitian:deskriptif,pengumpulan data secara retrospektif melalui data rekam medik pasien.Hasil: hasil analisis yang dapat diambil yaitu data kuantatif meliputi jumlah pasien glaukoma yang paling banyak yaitu berjenis kelamin perempuan sebanyak 46,90\%, jumlah pasien paling banyak yaitu berada pada kelompok umur > 65 (manula) sebesar $34.96 \%$, jumlah pasien berdasarkan diagnosis glaukoma yaitu glaukoma sudut tertutup sebesar $51,77 \%$, jumlah pasien penggolongan obat yang paling banyak digunakan adalah golongan beta bloker sebanyak 42,70\%, jumlah pasien berdasarkan rute pemberian obat yang paling banyak digunakan dengan rute pemberian tetes mata sebanyak $68,14 \%$, kemudian data kualitatif meliputi jumlah Resep obat glaukoma berdasarkan kesesuaian dosis yaitu $100 \%$ sesuai, jumlah potensi interaksi obat anti glaukoma adalah sebesar 19,46\%. Kesimpulan: Potensi interaksi obat anti glaukoma yaitu pada kombinasi obat timolol-brimodine dan betaxolol brimodine serta acetazolamide - glycerol dengan klasifikasi moderat : Cukup signifikan secara klinis. Biasanya menghindari kombinasi; menggunakannya hanya dalam keadaan khusus.
\end{abstract}

Kata kunci: Drug Related Problems, kombinasi obat, anti glaukoma.

\begin{abstract}
Background: In the world, glaucoma in the second ranks $(12,3 \%)$ after cataract $(47,8 \%)$ as the second leading cause of blindness. Drugs interactions is one of the Drug Related Problems (DRPs) which may affect therapy of patients. Objectivitas: Study of potential drugs interaction in out patients at one hospital in Bandung. Methode:Descriptive.collected data in medical record by restrospective. The Result: the results of the analysis that can be taken which includes the amount of Quantitative data, glaucoma patients are female as much as $46.90 \%$, highest number of patients that are in the group age $>65$ (seniors) amounted to $34.96 \%$, the number of patients based on the diagnosis of glaucoma is closed angle glaucoma amounted to $51.77 \%$, the number of patients the drug classification is the most widely used class of beta blockers as much as $42.70 \%$, the number of patients by the administration of drugs The most widely used route administration of eye drops as much as $68.14 \%$, and qualitative data include the number of Recipe glaucoma drug based on suitability dose is $100 \%$ suitable, the number of anti-
\end{abstract}


glaucoma drug interaction potential is equal to $19.46 \%$. Conclusion: The potential for drug interactions, namely the combination of anti-glaucoma drug timolol-brimodine betaxololbrimodine and acetazolamide - glycerol with moderate classification: at clinically significant, usually avoid combination; use them only in special circumstances.

Keywords : Drug Related Problems, drugs combination, antiglaucoma

\section{PENDAHULUAN}

Glaukoma merupakan penyebab kedua kebutaan di seluruh dunia. World Health Organization (WHO) memperkirakan pada tahun 2002 di seluruh dunia terdapat 37 juta orang mengalami kebutaan dan glaucoma menempati urutan kedua (12,3\%)setelah katarak $(47,8 \%)$ sebagai penyebab kebutaan. Diperkirakan pada tahun 2010 diperkirakan terdapat 60,5 juta penderita glaucoma diseluruh dunia dan jumlahnya meningkat pada 2020 menjadi 79,6 juta,kemudian diperkirakan pada tahun 2040 menjadi 111,8 juta (Quicley, 2006).

$$
\text { Glaukoma ditandai oleh }
$$

meningkatnya tekanan intraokular yang disertai oleh pencekungan diskus optikus dan pengecilan lapang pandang. Glaukoma dapat menyebabkan penyempitan lapang pandang bilateral progresif yang sering tidak terdeteksi sampai terjadi pengecilan lapang pandang yang ekstensif. Glaukoma merupakan penyakit yang tidak dapat dicegah, akan tetapi bila diketahui lebih dini dan diobati maka glaukoma dapat diatasi untuk mencegah kerusakan lanjut (Vaughan, 1998).

Mekanisme peningkatan tekanan intraokular pada pasien glaukoma adalah gangguan aliran keluar humor akueus akibat kelainan sistem drainase sudut kamera anterior (glaukoma sudut terbuka) atau gangguan akses humor akueus ke sistem drainase (glaukoma sudut tertutup).Pengobatan ditujukan untuk menurunkan tekanan intraokular dan apabila mungkin memperbaiki pathogenesis yang mendasarinya (Vaughan, 1998).
Semakin dini deteksi glaukoma maka akan semakin besar tingkat kesuksesan pencegahan kerusakan penglihatan. Meskipun belum ada cara untuk memperbaiki kerusakan penglihatan yang terjadi akibat glaukoma, pada kebanyakan kasus glaukoma dapat dikendalikan dengan terapi pengobatan yaitu dengan pemberian obat tetes sebagai terapi awal. Apabila glaukoma tidak dapat dikontrol dengan obat-obatan atau efek samping tidak dapat ditolerir, maka dapat dilakukan pembedahan untuk meningkatkan pembedahan untuk meningkatkan pengaliran cairan dari bilik anterior (Vaughan, 1998).

Tujuan terapi adalah untuk menurunkan tekanan intra ocular ke tingkat yang berhubungan dengan penurunan risiko kerusakan saraf optic. Terapi obat harus dipantau dengan pengukuran tekanan intra okular, pemeriksaan disk optik, penilaian bidang visual, dan evaluasi pasien untuk efek samping obat, interaksi obat dan kepatuhan pada terapi obat. Pasien yang tidak responsif atau tidak toleran dari obat harus beralih ke agen alternatif lain daripada diberikan obat tambahan. Banyak dokter lebih memilih untuk menghentikan semua obat pada pasien yang gagal untuk menanggapi topikal sederhana (Vaughan,1998).

Dengan meningkatnya kompleksitas obat-obat yang digunakan dalam pengobatan pada saat ini, dan berkembangnya polifarmasi, kemungkinan terjadinya interaksi obat sangat besar. Agar penggunaan obat tepat dan rasional perlu adanya pemantauan oleh seorang farmasis yaitu proaktif, mengantisipasi interaksi obat yang 
mungkin terjadi dan bertindak sebelum muncul masalah (Aslam, 2003).

Berdasarkan latar belakang tersebut, pemilihan obat yang akan digunakan pada pasien glaukoma harus sangat diperhatikan dan sesuai dengan faktor penyebab dari glaukoma. Penggunaan obat yang tidak sesuai dapat menimbulkan efek samping dan interaksi obat yang tidak diharapkan bahkan dapat menimbulkan reaksi merugikan yang dapat menghambat kerja obat dan tidak menghasilkan efek terapi yang diinginkan. Oleh karena itu untuk meningkatkan ketepatan dalam penggunaan obat pada pasien glaucoma perlu adanya kajian interaksi obat pada pasien glaucoma.

Penelitian ini bertujuan untuk mengetahui ketepatan penggunaan obat glaukoma dan menilai kefektifan penggunaan obat berdasarkan kajian potensi interaksi obat pada pasien penderita Glaukoma di salah satu rumah sakit di Bandung.

\section{METODE PENELITIAN}

\section{Penetapan Kriteria Pasien}

\section{Inklusi}

Semua pasien yang diikut sertakan dalam penelitian adalah pasien glaukoma yang mendapatkan terapi obat antiglaukoma

\section{Eksklusi}

Pasien yang diikut sertakan dalam penelitian adalah pasien yang termasuk kategori penderita glaukoma dan yang tidak mendapatkan terapi anti glaukoma.

\section{Penetapan Kriteria Obat}

Golongan obat yang diteliti adalah semua jenis obat yang diberikan pada pasien glaukoma yang melakukan rawat jalan di salah satu rumah sakit di Bandung.
Penetapan Kriteria Interaksi Obat

Standar Penggunaan obat adalah suatu acuan yang digunakan untuk mengevaluasi penggunaan obat. Persyaratan dari standar penggunaan obat ini harus obyektf, tegas, jelas didasarkan pada pustaka yang mutakhir dan secara internasional banyak digunakan, serta merefleksikan standar paktek medik dan pengalaman klinik medik, serta disetujui oleh staf medik. Standar penggunaan obat ini meliputi, indikasi, lama terapi, kontra indikasi, dosis, efek samping dan interaksi obat. Penelitian ini meliputi interaksi obat saja.

\section{Data dan Sumber Data Penelitian}

Data Restrospektif diambil dari rekam medik penderita rawat jalan di salah satu Rumah Sakit di Bandung yang telah selesai memperoleh pengobatan.

\section{Pengumpulan data}

Pengumpulan data dilakukan dengan mengumpulkan jenis data yang dibutuhkan dari sumber data yaitu rekam medik berupa data: Identitas penderita (meliputi: nama, usia, jenis kelamin), diagnose, proses pengobatan dan tindakan medik.

\section{Analisis Data}

Analisis data penelitian terdiri dari:

\section{Analisa Kuantitatif}

Analisis mengenai data untuk mengetahui pola penggunaan obat berdasarkan jumlah penderita berdasarkan jenis kelamin, jumlah penderita berdasarkan umur, jumlah penderita berdasarkan diagnosis, jumlah penderita berdasarkan golongan obat anti glaukoma yang digunakan, jumlah obat berdasarkan golongan farmakologi, rute pemberian, dan dokter penulis resep. 


\section{Analisis Kualitatif}

Analisis mengenai data yang digunakan untuk mengkaji secara ketepatan penggunaan obat berdasarkan standar penggunaan obat yang ditetapkan, meliputi indikasi, dosis, kombinasi obat, interaksi obat dan duplikasi penggunaan.

\section{Pengambilan Kesimpulan}

Analisis dari hasil penelitian dilakukan secara kuantitatif dan kualitatif terhadap penderita glaukoma dan penggunaan obat-obat glaukoma. Analisis kuantitatif untuk mengetahui jumlah penderita serta jumlah penggunaan obat glaukoma berdasarkan kebutuhan klink. Diambil kesimpulan untuk mengetahui ketepatan dan masalah dalam penggunaan obat.

\section{HASIL PENELITIAN DAN PEMBAHASAN}

Berdasarkan hasil penelitian yang didapat periode januari sampai dengan maret 2015 untuk pasien glaukoma adalah

Tabel 1.Jumlah Pasien Berdasakan Jenis Kelamin

\begin{tabular}{lll}
\hline Jenis Kelamin & Jumlah & Persentase (\%) \\
\hline Laki - Laki & 106 & 46,90 \\
Perempuan & 120 & 53.10 \\
\hline Jumlah & 226 & 100,00 \\
\hline
\end{tabular}

Berdasarkan data diatas, jumlah pasien glaukoma di poli glaukoma periode bulan Januari sampai dengan maret 2015 adalah 226 orang. Berdasarkan jenis kelamin, jumlah penderita glaukoma yang paling banyak berjenis kelamin perempuan dengan jumlah pasien sebesar 53,10 \%, sedangkan penderita glaukoma dengan jenis kelamin laki-laki sebesar 46,90\%. Pasien perempuan beresiko mendapatkan penyakit glaukoma, hal ini kemungkinan akibat sudut bilik mata depan perempuan (volume 10\%) lebih dangkal daripada laki-laki. (Stamper RL, 2009)

Tabel 2.Jumlah Pasien Berdasakan Kelompok Umur

\begin{tabular}{llll}
\hline Umur (Tahun) & & Jumlah & Persen $(\%)$ \\
\hline Masa balita & $=(0-5)$ & 0 & 0 \\
Kanak- kanak & $=(5-11)$ & 0 & 0 \\
Remaja Awal & $=(12-16)$ & 2 & 0,88 \\
Remaja Akhir & $=(17-25)$ & 6 & 2,65 \\
Dewasa awal & $=(26-35)$ & 9 & 3,98 \\
Dewasa akhir & $=(36-45)$ & 16 & 7,09 \\
Lansia awal & $=(46-55)$ & 37 & 16,37 \\
Lansia akhir & $=(56-65)$ & 77 & 34,07 \\
Manula & $=>65$ & 79 & 34,96 \\
\hline Jumlah & & 226 & 100,00 \\
\hline
\end{tabular}

Sumber: kategori umur menurut Depkes RI (2009) 
Berdasarkan tabel diatas jumlah penderita glaukoma terbanyak berada pada kelompok umur tahun > 65 (manula) sebesar $34.96 \%$, hal ini disebabkan pada kelompok umur ini mulai munculnya faktor resiko yang dapat menyebabkan glaukoma, seperti hipertensi, diabetes, dan lain-lain. Faktor lain adalah secara fatofisiologis mekanisme pengaliran secara berangsurangsur dapat menjadi tersumbat dengan penuaan umur, sebagai akibatnya humor akueus tidak dapat keluar. Oleh karenanya tekanan intraokular dapat meningkat.(Vaughan, 1998)

Tabel 3. Diagnosis Glaukoma

\begin{tabular}{ccc}
\hline Diagnosis Glaukoma & Jumlah Pasien & Persentase \\
\hline Glaukoma sudut tertutup & 117 pasien & $51,77 \%$ \\
Glaukoma sudut terbuka & 109 pasien & $48,23 \%$ \\
\hline Jumlah pasien & 226 pasien & $100 \%$ \\
\hline
\end{tabular}

Dari pengambilan data bulan Januari- maret 2015, didapatkan penderita glaukoma sudut tertutup lebih banyak dibandingkan glaucoma sudut terbuka, glaukoma sudut tertutup sendiri dapat terjadi karena pengeluaran humor akuos tersendat akibat tertutup iris yang menjadi melengkung, terdapat sebanyak 117 pasien menderita glaukoma sudut tertutup, dan glaukoma sudut terbuka 109 pasien, glaukoma sudut terbuka salah satunya timbul karena penebalan lamella pada sekitar jalur trabekular yang menyebabkan terhambatnya pengeluaran humor akuos ke jalur trabekular. Sebenarnya terdapat jenis glaukoma lainnya yaitu glaukoma kongenital dan secondary glaucoma, tetapi kedua jenis glaukoma tersebut tidak termasuk ke dalam penelitan karena untuk glaukoma kongenital diderita oleh pasien anak, sehingga tidak masuk kriteria inklusi penelitian, dan untuk secondary glaucoma merupakan glaukoma yang terjadi akibat gangguan mata lain yang dialami pasien, seperti pascaoperasi intraokular.(Vaughan, 1998)

Tabel 4.Jumlah Obat Berdasarkan Penggolongan Obat Glaukoma

\begin{tabular}{|c|c|c|}
\hline Golongan Obat Glaukoma & Jumlah & Persentase \\
\hline$\beta$-bloker & & 42,62 \\
\hline 1. Timolol $0,5 \%$ & 195 & \\
\hline 2. Betaxolol & 10 & \\
\hline Karbonik Anhidrase Inhibitor & & 28,07 \\
\hline Topikal & & \\
\hline 1. Dorzolamide & 46 & \\
\hline 2. Brinzolamide & 19 & \\
\hline Sistemik & & \\
\hline 1. Acetazolamide & 70 & \\
\hline Analog Prostaglandin & & 20,99 \\
\hline 1. Latanaprost & 100 & \\
\hline 2. Travaprost & 1 & \\
\hline$\alpha 2$-Agonist adrenergic & & 8,32 \\
\hline 1. Brimonidine & 40 & \\
\hline Jumlah & 481 & 100 \\
\hline
\end{tabular}


Berdasarkan tabel diatas dapat diketahui jumlah pemakaian golongan obat glaukoma terbanyak adalah golongan $\beta$-bloker dengan jumlah penggunaan sebesar 42,62 \%, hal ini disebabkan oleh hasil penurunan tekanan intraokular yang cukup signifikan, senyawa beta bloker memberikan efek hipotensif dengan cara menrunkan produksi cairan humor akueus dari badan siliar.dan faktor efisiensi besarnya biaya yang dikeluarkan oleh pasien. Golongan obat glaukoma terbesar kedua adalah golongan obat karbonik anhidrase inhibitor sebesar $28,07 \%$ karena dapat menurunkan tekanan intraocular hinga 15-26\% dan untuk karbonik anhidrase inhibitor topical umumnnya bertoleransi baik,sedangkan untuk karbonik anhidrase inhibitor sistemik memakan waktu lama untuk mencapai efek terapi yang diharapkan, yaitu efek dimulai dalam 10 menit dengan efek puncak dalam 30 menit, dan digunakan secara oral (sistemik).

Selanjutnya, golongan obat terbesar ketiga yang paling banyak digunakan adalah golongan obat Analog Prostaglandin dengan pemakaian obat sebesar 20,99\% hal ini disebabkan dapat menurunkan tekanan intraokular dengan cara meningkatkan uveosklera dan penurunan perluasan pengeluaran trabekular dari cairan humor akueus, dan golongan obat glaukoma yang paling sedikit digunakan adalah golongan obat $\alpha_{2}$-Agonist Adrenergic dengan jumlah penggunaan sebesar $8,32 \%$, dikarenakan efektif dalam mencegah atau mengkontrol peningkatan tekanan intraocular pasca operasi atau pasca laser.(Diphiro, 2008)

Tabel 5. Jumlah Pasien Berdasarkan Rute Pemberian Obat

\begin{tabular}{lll}
\hline Nama Obat & Jumlah & Persentase \\
\hline Tetes Mata & 154 & 68,14 \\
Oral & 0 & 0 \\
Tetes Mata + Oral & 72 & 31,86 \\
\hline Jumlah & 226 & 100 \\
\hline
\end{tabular}

Berdasarkan tabel di atas, dapat diketahui metode rute pemberian obat terhadap pasien glaukoma dilakukan dengan dua rute, yaitu tetes mata dan oral, maupun kombinasi antara tetes mata dan oral. Jumlah pasien yang paling banyak berdasarkan rute pemberian adalah pemberian dengan rute tetes mata sebesar $68,14 \%$, karena pemakaian obat tetes mata lebih memberikan efek yang lebih cepat dibandingkan secara sistemik yang memakan waktu lama untuk mencapai efek terapi yang diharapkan, yaitu efek dimulai dalam 10 menit dengan efek puncak dalam 30 menit, dan digunakan secara oral /sistemik. (Vaughan, 1998). 
Tabel 6. Jumlah R/ Obat Glaukoma Berdasarkan Kesesuian dan Ketidaksesuaian Dosis

\begin{tabular}{llllcc}
\hline \multirow{2}{*}{ Nama Obat } & \multicolumn{2}{c}{ Ketentuan } & \multicolumn{2}{c}{ Ketepatan dosis } & \multicolumn{2}{c}{ Dosis tidak sesuai } \\
\cline { 2 - 6 } & \multicolumn{1}{c}{ Dosis } & Jumlah & $\begin{array}{c}\text { Persen } \\
(\%)\end{array}$ & Jumlah & $\begin{array}{c}\text { Persentase } \\
(\%)\end{array}$ \\
\hline Timolol Maleate & Sehari 2x 1 tetes & 195 & 40,21 & - & - \\
Dorzolamide & Sehari 3x 1 tetes & 46 & 9,49 & - & - \\
Latanoprost & Sehari 1x 1 tetes & 100 & 20,62 & - & - \\
Brimonidine & Sehari 3x 1 tetes & 40 & 8,24 & - & - \\
Asetazolamide & Sehari 3 x 1 tab & 70 & 14,43 & - & - \\
Gliserin & Sehari 1 x 1 btl & 5 & 1,03 & - & - \\
Betaxolol & (50\% ) & & & & - \\
Brinzolamide & Sehari 2 x 1 tetes & 10 & 2,06 & - & - \\
\hline Jumlah & Sehari 2 x 1 tetes & 19 & 3,92 & - & - \\
\hline
\end{tabular}

Sumber: Kategori Dosis menurut Diphiro

Berdasarkan tabel diatas, dapat dilihat jumlah R/ obat glaukoma pada pasien berdasarkan ketepatan dosis yaitu dari hasil perhitungan yang diperoleh dari data rekam medik menunjukan bahwa dosis glaukoma yang digunakan di Rumah sakit Mata Cicendo untuk pasien glaukoma di poli glaukoma semuanya sesuai. Perhitungan dosis dilakukan berdasarkan umur pasien serta membandingkan dengan literatur atau pustaka yang sah dan mutakhir. dikatakan dosis tidak sesuai jika pemberian obat kurang dari seharusnya yang diperlukan, sehingga pengobatan terapi tidak tercapai sesuai dengan yang dinginkan. Sedangkan dosis sesuai jika pemberian obat sesuai dengan dosis yang diperlukan oleh pasien. (Diphiro)

Tabel 7. Kajian Potensi Interaksi Obat Glaukoma

\begin{tabular}{|c|c|c|c|c|}
\hline No & Nama Obat & $\begin{array}{l}\text { Jumlah } \\
\text { Pasien }\end{array}$ & $\begin{array}{l}\text { Mekanisme } \\
\text { Interaksi }\end{array}$ & Klasifikasi \\
\hline 1 & Timolol 0,5\% + brimonidine +dorzolamide & 5 & Farmakodinamika & Moderat \\
\hline 2 & Timolol $0,5 \%+$ brimonidine + brinzolamide & 2 & Farmakodinamika & Moderat \\
\hline 3 & Timolol $0,5 \%$ + brimonidine +latanaprost & 2 & Farmakodinamika & Moderat \\
\hline 4 & Timolol $0,5 \%+$ brimonidine+prednisolone & 1 & Farmakodinamika & Moderat \\
\hline 5 & Betaxolol $0,5 \%$ +dorzolamide +brimonidine & 3 & Farmakodinamika & Moderat \\
\hline 6 & Timolol $0,5 \%+$ brimonidine + acetazolamide & 1 & $\begin{array}{l}\text { Farmakodinamika } \\
\text { Farmakokinetika }\end{array}$ & Moderat \\
\hline 7 & Timolol $0,5 \%+$ acetazolamide + glyserol & 1 & $\begin{array}{l}\text { Farmakodinamika } \\
\text { Farmakokinetika }\end{array}$ & Moderat \\
\hline 8 & $\begin{array}{l}\text { Timolol } 0,5 \%+\text { latanaprost }+ \text { brimonidine+ } \\
\text { (sodium chloride+kalium chloride) }\end{array}$ & 2 & Farmakodinamika & Moderat \\
\hline 9 & $\begin{array}{l}\text { Timolol } 0,5 \%+\text { latanaprost }+ \text { dorzolamide }+ \\
\text { brimonidine }\end{array}$ & 2 & Farmakodinamika & Moderat \\
\hline 10 & $\begin{array}{l}\text { Timolol } 0,5 \%+\text { brinzolamide }+ \text { brimonidine }+ \\
\text { (sodium chloride+kalium chloride) }\end{array}$ & 3 & Farmakodinamika & Moderat \\
\hline
\end{tabular}


11 Timolol $0,5 \%$ + dorzolamide + brimonidine+ (sodium chloride+kalium chloride)

12 Timolol $0,5 \%+$ prednisolone+dorzolamide+ brimonidine

13 Timolol $0,5 \%+$ brimonidine + asetazolamide + 1 aspartate

14 Timolol 0,5\% + glyserol +acetazolamide + 1 aspartate

15 Timolol $0,5 \%+$ tropin $0,5 \%$ +brimonidine+ asetazolamide

16 Timolol 0,5\%+latanaprost+ dorzolamide+ brimonidine+(sodium chloride+kalium chloride)

17 Timolol 0,5\% + fluemetholone+dorzolamide+ brimonidine+(sodium chloride + kalium chloride)

18 Timolol 0,5\% +brimonidine+ prednisolone+ acetazolamide +1 aspartate

19 Timolol 0,5\%+betaxolol+brimonidine+ acetazolamide +1 aspartate
$1 \quad$ Farmakodinamika Moderat

$1 \quad$ Farmakodinamika Moderat

Farmakokinetika

10 Farmakodinamika Moderat

Farmakokinetika

4 Farmakodinamika Moderat

Farmakokinetika

1 Farmakodinamika

Moderat

Farmakokinetika

1 Farmakodinamika Moderat

1 Farmakodinamika Moderat

2 Farmakodinamika Moderat

Farmakokinetika

1 Farmakodinamika Moderat

Farmakokinetika

\section{4}

Persentase potensi interaksi Obat

Dari data diatas terdapat interaksi beberapa kombinasi yang potensi terjadinya interaksi obat diantaranya adalah

\section{Timolol-brimodine \& betaxolol- brimodine}

Setelah menggunakan brimonidine mata, beberapa obat dapat diserap ke dalam aliran darah dan kadang-kadang menghasilkan efek samping kardiovaskular seperti penurunan tekanan darah dan detak jantung. Menggabungkan dengan timolol tetes mata atau obat lain yang juga dapat memiliki efek ini dapat meningkatkan risiko. Sehingga dapat mengalami sakit kepala, pusing, ringan, pingsan, dan / atau perubahan denyut nadi atau jantung berdetak. Efek samping yang paling mungkin untuk dilihat pada awal pengobatan, menyusul peningkatan dosis, atau ketika pengobatan restart setelah gangguan.

Manajemen: Tekanan darah dan denyut nadi harus dipantau secara teratur ketika agonis reseptor topikal alpha-2 adrenergic yang diresepkan dalam kombinasi dengan obat kardiovaskular. Pasien harus dianjurkan untuk memberitahu dokter mereka jika mereka mengalami pulsa lambat, denyut jantung tidak teratur, pusing, ringan, atau sinkop. (Nordlund JR) 


\author{
Klasifikasi Moderat: Cukup \\ signifikan secara klinis. Biasanya \\ menghindari kombinasi; \\ menggunakannya hanya dalam keadaan \\ khusus.
}

\section{Acetazolamide - glyserol}

Menggabungkan obat-obat ini, terutama dalam jangka waktu lama, dapat meningkatkan risiko dehidrasi dan elektrolit kelainan. Dalam kasus yang parah, dehidrasi dan elektrolit kelainan dapat menyebabkan ritme teratur jantung, kejang, dan masalah ginjal. Penggunaan kronis atau penyalahgunaan obat pencahar dapat mempotensiasi efek farmakologis dari diuretik. Obat pencahar dapat menyebabkan kerugian yang signifikan dari cairan dan elektrolit, termasuk sodium, kalium, magnesium dan seng, dan efek ini mungkin aditif bagi mereka diuretik. Manajemen: Secara umum, obat pencahar hanya boleh digunakan pada jangka pendek, secara intermiten dalam dosis yang direkomendasikan. Selama penggunaan bersamaan dengan diuretik, pasien harus disarankan untuk menghubungi dokter mereka jika mereka mengalami tanda-tanda dan gejala penipisan cairan dan elektrolit seperti pusing, ringan, mulut kering, haus, kelelahan, kelemahan, lesu, kram otot, penurunan buang air kecil, hipotensi postural , dan takikardia. Jika pemeliharaan keteraturan usus diperlukan, pasien harus dianjurkan untuk berolahraga dan meningkatkan serat dalam diet dan / atau mempertimbangkan penggunaan obat pencahar pembentuk sampah. (Muller-Lissner SA)

$$
\text { Klasifikasi Moderat: Cukup }
$$

signifikan secara klinis. Biasanya menghindari kombinasi; menggunakannya hanya dalam keadaan khusus.

\section{KESIMPULAN}

Dari hasil analisis mengenai penggunaan obat glaukoma dan potensi interaksi obat glaukoma pada pasien rawat jalan di Rumah Sakit Mata Cicendo dapat disimpulkan bahwa potensi interaksi obat anti glaukoma yaitu pada kombinasi obat timolol-brimodine \& betaxolol brimodine serta acetazolamide - glycerol dengan klasifikasi moderat: Cukup signifikan secara klinis. Biasanya menghindari kombinasi; menggunakannya hanya dalam keadaan khusus.

\section{DAFTAR PUSTAKA}

1. Quicley HA, Broman AT. The number of people with glaucoma worldwide in 2010 and 2020. Br J Opthalmol. 2006;90:262-7.

2. Vaughan, Daniel., Taylor Asbury, Paul Riordan-Eva (1998). General Ofthalmology Appleton \& Lange. $15^{\text {th }}$ Revised Edition.

3. Stockley, Ivan.,H. (2009). Drug Interaction. London, UK :The pharmaceutical Press

4. Rova Virgana (2007) Ocular Pharmacotherapy in Glaucoma, Bagian Ilmu Kesehatan Mata Fakultas Kedokteran Unpad Rumah Sakit Mata Cicendo Bandung

5. Aslam, Mohamed. (2003). Farmasi klinis: Menuju Pengobatan Rasional dan Perhargaan Pilihan Pasien. Universitas Surabaya.

6. Dipiro, Joseph T., Robert L. Talbert, Gary C. Yee, dkk (2008) .Pharmacotheraphy "A Phatophisiologis Approach", $7^{\text {th }}$ Ed, The Mcdraw - Hill Companies.

7. King $\mathrm{MH}$, Richards DW "Near syncope and chest tightness after administration of apraclonidine before argon laser iridotomy." Am J Ophthalmol 110 (1990): 308-9

8. Nordlund JR, Pasquale LR, Robin AL, Rudikoff MT, Ordman J, Chen KS, Walt J "The cardiovascular, pulmonary, and ocular hypotensive 
effects of $0.2 \%$ brimonidine." Arch Ophthalmol 113 (1995): 77-83

9. Muller-Lissner SA "Adverse effects of laxatives: fact and fiction." Pharmacology 47 (1993): 138-45

10. Blumenthal M, Goldberg A, Brinckmann J, eds. "Herbal
Medicine: Expanded Commission E Monographs." Newton, MA: Integrative Medicine Communications (2000):

11. Chin RL "Laxative-induced hypokalemia." Ann Emerg Med 32 (1998): 517-8 